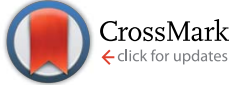

Cite this: RSC Adv., 2017, 7, 3369
Received 30th October 2016 Accepted 23rd November 2016

DOI: 10.1039/c6ra26048a

www.rsc.org/advances

\section{Fabrication of HA/PEI-functionalized carbon dots for tumor targeting, intracellular imaging and gene delivery}

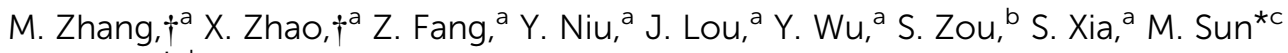 \\ and F. Du*ab
}

Carbon quantum dots (CDs) as emerging carbon nano-materials have attracted tremendous attention in biomedical fields due to unique properties. In this study, hyaluronate (HA) and polyethylenimine (PEI) functionalized carbon dots (HP-CDs) were synthesized by a facile bottom-up method for tumor targeting and gene delivery. After HA modification, the HP-CDs exhibited superior dispersibility in water and good biocompatibility and were internalized readily into the cytoplasm of cancer via HA-receptor mediated endocytosis. Meanwhile, the HP-CDs with PEI functionalization were shown to have excellent gene condensation capability via electrostatic attraction and protective capacity by preventing nuclease degradation. By virtue of good photoluminescence properties, the HP-CDs as a gene carrier were successfully applied to intracellular imaging and gene delivery. Taken together, the resultant HP-CDs displayed great potential in tumor targeting, intracellular imaging and gene delivery.

\section{Introduction}

Recently, fluorescent carbon dots (CDs), ${ }^{\mathbf{1}, \mathbf{2}}$ a new member of the nano carbon materials, firstly produced by Sun and co-workers ${ }^{3}$ have drawn extensive attention in the nanotechnology field. ${ }^{\mathbf{1}}$ Similar to metallic quantum dots, CDs can also emit multicolour bright fluorescence by adjusting the particle size., ${ }^{\mathbf{4 , 5}}$ However, CDs show significant advantages due to their water dispensability, chemical inertness, good photostability, low cytotoxicity, and excellent biocompatibility compared with organic dyes and other semiconductor nanodots with heavy metal elements. The above-mentioned capabilities of CDs endow them a wide range of technology applications in gene/ drug delivery, ${ }^{6,7}$ bio-imaging, ${ }^{8}$ photocatalysis, ${ }^{9}$ bio-sensing, ${ }^{10}$ optoelectronic devices, ${ }^{11}$ energy conversion/storage devices ${ }^{\mathbf{1 2}}$ and other bio-applications. ${ }^{13}$

Up to now, the ways methods of synthesizing CDs are classified into two groups, including the top-down and bottom-up methods. ${ }^{\mathbf{1 1 4}}$ Top-down methods generally have to break down the large carbonaceous materials and polymerize into the nanoparticles by using physical or chemical methods, but the fluorescence of CDs was relatively low. On the contrary, the

\footnotetext{
${ }^{a}$ School of Medicine, Jiangsu University, Zhenjiang, 212013, P. R. China. E-mail: xiasheng1519@163.com; biodfy@ujs.edu.cn

${ }^{b}$ Department of Hepatosis, The Third Hospital of Zhenjiang Affiliated to Jiangsu University, Zhenjiang, Jiangsu, P. R. China

${ }^{c}$ Department of Clinical Laboratory, Affiliated Yancheng Hospital, School of Medicine, Southeast University, Yancheng, Jiangsu 224001, P. R. China

$\dagger$ These authors contributed equally to this work.
}

bottom-up methods involves the carbonization of small molecular precursors, which are carbon-containing materials and passivation agents into the CDs, including hydrothermal carbonization, ${ }^{15,16}$ micro-wave hydrolysis ${ }^{17}$ and combustion methods. ${ }^{18}$ The passivation agents always contain terminal $\mathrm{NH}_{2}$ groups, use of which illustrated that nitrogen-containing groups acting as auxochromes could dramatically improve the photoluminescence of CDs. ${ }^{19}$ It is more conducive to control the chemical compositions and physical characters by bottom-up compared with top-down methods. Bottom-up methods were therefore mostly adopted for the synthesis of various CDs.

Hyaluronic acid (HA), a natural formation high molecular weight anionic mucopolysaccharide, has the advantages of good biocompatibility, biodegradability, non-immunogenicity and nontoxic, which endow HA grant applications in biomedicine. ${ }^{\mathbf{2 0 , 2 1}}$ Most importantly, HA can bind with targeting ligand CD44, which are overexpressed in many kinds of tumor cells. $^{22-25}$ In recent years, HA-drug conjugate, HA-amphiphilic derivatives, HA surface modified and HA gene carriers targeting drug systems have been widely studied and applied to active tumor targeting. ${ }^{26-30}$ Moreover, polyethyleneimine (PEI) was first reported as gene delivery vector by Boussif and his coworkers in $1995,{ }^{31}$ which is rated as the fastest growing, the most well researched and the most potential non-viral gene delivery vector at present. For transfection efficiency, the desired PEI molecular weight range is from $11.9 \times 10^{3}$ to $70.0 \times$ $10^{3}$ and branched 25k PEI had the highest transfection efficiency. The unique proton sponge mechanism of PEI is beneficial for endosomal escape in cells. ${ }^{32-34}$ In view of their transfection capability, PEI has already been applied for 
preparation of multifunctional fluorescent CDs using distinct carbonization method. ${ }^{35,36}$ Liu et al. has already constructed CDs based on PEI, but lacked of targeting modification and hardly been used as tumour-targeting imaging. ${ }^{37}$ In this study, multifunctional CDS were synthesized by facile bottom-up method for tumour targeted and gene delivery via hydrothermal reaction of HA used as targeting ligand and PEI used as transfection motif.

\section{Experimental}

\subsection{Materials}

Branched polyethyleneimine with $M_{\mathrm{w}}$ of $25 \mathrm{kDa}$ (water-free) and cell counting kit-8 (cck-8) were purchased from Sigma-Aldrich (New York, USA). Hyaluronic acid sodium salt $\left(M_{\mathrm{w}}, 200-400\right.$ $\mathrm{kDa}$ ) from Streptococcus equi was obtained from Aladdin (Shanghai, China). RT-PCR kit were purchased from Promega (Madison, WI, USA). Lyso Tracker Red was purchased from Life technology (New York, USA). PCR green master mix was obtained from Thermo (New York, UAS). PCR primer and Plasmid DNA extract kit was obtained from Shanghai Sangon Company (Shanghai, China). Fetal bovine serum was purchased from Excell (Shanghai, China). Dulbecco's Minimum Essential Medium (DMEM) was purchased from Invitrogen China Limited. All chemicals were of analytical grade and were used without further purification.

\subsection{Synthesis of HP-CDs}

$0.14 \mathrm{~g}$ HA, $0.8 \mathrm{~mL}$ commercial branched $25 \mathrm{k}$ PEI $\left(1.030 \mathrm{~g} \mathrm{~mL}^{-1}\right)$ and $\mathrm{dd}_{2} \mathrm{O}$ up to $20 \mathrm{~mL}$ were mixed under vigorous stirring to form a homogeneous solution in a common $100 \mathrm{~mL}$ beaker. Then the transparent solution was transferred into a $50 \mathrm{~mL}$ Teflon-lined stainless steel autoclave and heated at $180{ }^{\circ} \mathrm{C}$ for $4 \mathrm{~h}$. When cooled down to room temperature, the colourchanged solution was centrifuged at $2000 \mathrm{rpm}$ for $15 \mathrm{~min}$ to remove the black precipitates. The supernatant was transferred into a dialysis membrane (MWCO of 1000) and was dialyzed against pure water for 4 days to remove residues. Finally, the brown-yellow solution was collected and freeze-dried using a vacuum freeze dryer at $-50{ }^{\circ} \mathrm{C}$ for 72 hours. The HP-CDs powder were obtained and saved for further characterization.

\subsection{Instrumentation and characterizations}

The morphologies of the HP-CDs were examined by high resolution transmission electron microscopy (HRTEM) on a JEM2100 microscope (Jeol, Japan) with an accelerating voltage of $200 \mathrm{kV}$. UV-Vis absorption was characterized by UV-2450 UV-Vis Spectrophotometer (Shimadzu, Japan). PL emission measurements were performed using Cary Eclipse Fluorometer (Varian, America). The chemical structure of HP-CDs was identified by Fourier Transform Infrared (FT-IR) spectra (Nicolet Nexus 470, America). The crystal structure of the HP-CDs was characterized via X-ray diffraction (XRD) patterns on a Rigaku-D/MAX2500 diffractometer (Rigaku, Japan) equipped with $\mathrm{Cu} \mathrm{K} \alpha(\lambda=$ $0.15405 \mathrm{~nm}$ ) radiation at a scanning speed of $4^{\circ} \min ^{-1}$ in the range from $5^{\circ}$ to $80^{\circ}$. The surface compositions of HP-CDs were identified by X-ray photoelectron spectroscopy (XPS) on Escalab 250Xi (Thermo Scientific, America).

\subsection{Cell viability assay}

The influence of HP-CDs on cell viability was studied via Cell Counting Kit 8 assay (CCK-8 assay). MGC-803 cells (gastric cancer cells, ATCC number: TCP-1008) were seeded in a 96-well plate at a density of $3 \times 10^{3}$ cells per well and cultured at $37^{\circ} \mathrm{C}$ in $5 \% \mathrm{CO}_{2}$ incubator for 24 hours, then using DMEM containing different concentrations of HP-CDs $\left(0 \mu \mathrm{g} \mathrm{mL} \mathrm{m}^{-1}, 25 \mu \mathrm{g} \mathrm{mL}{ }^{-1}\right.$, $50 \mu \mathrm{g} \mathrm{mL} L^{-1}, 100 \mu \mathrm{g} \mathrm{mL} \mathrm{m}^{-1}$ and $200 \mu \mathrm{g} \mathrm{mL}{ }^{-1}$ ) replacing the growth medium. After incubation for another 4 hours, adding $10 \mu \mathrm{L}$ CCK-8 solution to each well, cells were incubated for 4 hours in a dark place. The absorbance was measured at $490 \mathrm{~nm}$ using Synergy HT Multi-Mode Microplate Reader (Bio Tek, Winooski, VT, USA). Non-treated cells (in DMEM) were used as control, and the relative cell viability (mean $\mathrm{SD}, n=5$ ) was expressed as $\mathrm{Abs}_{\text {sample }} / \mathrm{Abs}_{\text {control }} \times 100 \%$.

\subsection{Hemolytic test}

Briefly, 19-21 g, ages of 6 weeks female BALB/c mice were kindly prepared by Animal Management Rules of the Ministry of Health of the People's Republic of China, then taking about 3 $\mathrm{mL}$ blood by removing eyeball, stabilized with heparin sodium, centrifuged (1, $200 \mathrm{rpm}, 15$ minutes) to remove the supernatant according to the literature, ${ }^{40}$ washed with PBS for five times to obtain the mouse red blood cells (MRBCs). Diluting ten times with PBS, 0.1 mL MRBCs were transferred into $1.5 \mathrm{~mL}$ tubes prefilled with $0.9 \mathrm{~mL}$ PBS containing different particle concen-

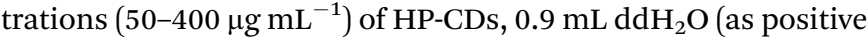
control), and $0.9 \mathrm{~mL}$ PBS (as negative control), respectively. The mixture was incubated for 2 hours at room temperature after a gentle shaking, then centrifuged at $12000 \mathrm{rpm}$ for 1 minute. Finally, the photographs of all the samples were taken and the absorbance of the supernatant (hemoglobin) was measured by a UV-2450 UV-Vis spectrophotometer. The hemolysis percentages of different samples were calculated by dividing the difference in absorbance among the sample, the positive and negative control at $541 \mathrm{~nm}$.

\subsection{Cell imaging and labeling}

Hela cells (Henrietta Lacks strain of cancer cells, ATCC number: CCL-2) were chosen to demonstrate the feasibility of HP-CDs for cell imaging. Hela cells were seeded at a density of $0.8 \times 10^{5}$ per well in a 24-well plate which has already covered $14 \mathrm{~mm}$ diameter glass coverslips. The cells were cultured in DMEM containing $10 \%$ FBS and incubated at $37{ }^{\circ} \mathrm{C}$ and $5 \% \mathrm{CO}_{2}$ overnight. The original supernate was discard and HP-CDs mixed with culture medium at $100 \mu \mathrm{g} \mathrm{mL} \mathrm{m}^{-1}$ were join in the holes. Cells were incubated at $37{ }^{\circ} \mathrm{C}$ under $5 \% \mathrm{CO}_{2}$ for $6 \mathrm{~h}$. After that, the supernate was discard and cells were incubated with prediluted Lyso Tracker (60 nM) for 90 minutes. Three times after washing, cells were fixed by $4 \%$ paraformaldehyde for 30 minutes at room temperature. After washing with PBS for 3 times, pre-diluted Hoechst $33342\left(5 \mu \mathrm{g} \mathrm{mL}^{-1}\right)$ was added to each hole for half an hour at room temperature to staining the 
nucleus. Three times after washing, the coverslips was taken out and mounted by resin. Then confocal lasers scanning fluorescence microscopy (Zeiss LSM-710) was used to observe the fluorescence in the cells with $496 \mathrm{~nm}$ laser to excite the HP-CDs.

\subsection{Measurement of CD44 expressed by PCR}

MGC-803 cells were seeded in six-well plates at $4 \times 10^{5}$ per well and incubated at $37{ }^{\circ} \mathrm{C}$ and $5 \% \mathrm{CO}_{2}$ for $24 \mathrm{~h}$. Then $0 \mu \mathrm{g} \mathrm{mL}{ }^{-1}$, $100 \mu \mathrm{g} \mathrm{mL}{ }^{-1}, 200 \mu \mathrm{g} \mathrm{mL}{ }^{-1}, 300 \mu \mathrm{gL}^{-1}$ and $400 \mu \mathrm{g} \mathrm{mL}{ }^{-1} \mathrm{HP}-$ CDs solution were added into each well respectively. Total RNA of the cells in each well were extracted after incubated for $6 \mathrm{~h}$. Briefly, $0.1 \mu \mathrm{g}$ of the total RNA of each well was first reverse transcribed into cDNA using the reverse transcription system. Subsequently, $2 \mu \mathrm{L}$ of the resultant cDNA was amplified by Thermo® Green Master Mix. PCR was performed in PTC-200 Peltier thermal cycler with the following program: an initial denaturation at $94{ }^{\circ} \mathrm{C}$ for $3 \mathrm{~min}$ followed by 30 cycles (for CD44 gene and GAPDH gene) at $94{ }^{\circ} \mathrm{C}$ for $30 \mathrm{~s}, 56^{\circ} \mathrm{C}$ for $30 \mathrm{~s}$, and $72{ }^{\circ} \mathrm{C}$ for $30 \mathrm{~s}$. After the last cycle, the program was ended by a final extension at $72{ }^{\circ} \mathrm{C}$ for $10 \mathrm{~min}$. The sequences of the PCR primers used as follows:

CD44 forward primer: $5^{\prime}$-CTACAGCATCTCTCGGAC- $3^{\prime}$

CD44 reverse primer: $5^{\prime}$-GTCTCAAATCCGATGCT C- $3^{\prime}$;

GAPDH forward primer: $5^{\prime}$-TGGGTGTGAACCATGAGAAG- $3^{\prime}$

GAPDH reverse primer: $5^{\prime}$-GAGTCCTTCCACGATACCAAAG- $3^{\prime}$.

The electrophoretic showed the difference of each PCR product by $3 \%$ agarose gel, which run in a $40 \mathrm{mM}$ TAE and stained using ethidium bromide (EB, $0.5 \mathrm{mg} \mathrm{mL}^{-1}$ ).

\subsection{Flow cytometry}

Hela cells were seeded in three wells of six-well plates at $3 \times 10^{4}$ per well and incubated at $37^{\circ} \mathrm{C}$ and $5 \% \mathrm{CO}_{2}$ for 24 hours. In the three wells, the first well was negative control, the second well was HA participating group, the third well was HP-CDs group. HA dilution solution ( $2 \mathrm{~mL}, 0.1 \mathrm{~g}$ HA dissolved in $10 \mathrm{~mL}$ DMEM with $10 \%$ FBS) was added in the second well. After $1 \mathrm{~h}$ later, the HA dilution solution was discard and $300 \mu \mathrm{g} \mathrm{mL}{ }^{-1}$ HP-CDs solution was added to the second and third well. All of three wells of cells were digested for flow cytometry after $6 \mathrm{~h}$ incubation to detecting the change of fluorescence intensity.

\subsection{Gel retardation assay}

The gene condensation capability of HP-CDs was evaluated by agarose gel electrophoresis. Plasmid at concentration of $640 \mathrm{ng}$ $\mu \mathrm{L}^{-1}$ was chosen as the DNA carried by as-prepared HP-CDs. HP-CDs solution was pre-diluted at concentration of $400 \mathrm{ng}$ $\mu \mathrm{L}^{-1}$. The DNA and HP-CDs were complexes at different weight ratios from $1: 0$ to $1: 6$ for half an hour while the weight of DNA is invariably $640 \mathrm{ng}$. However with the increasing weight of HPCDs, the volume of HP-CDs solution is also increased from 0 , 1.6, 3.2, 4.8, 6.3, 7.9, 9.5 $\mu \mathrm{L}$. Then the DNA/HP-CDs mixture was added to each well loaded with loading buffer in $1 \%$ agarose gel. After gel electrophoresis for 30 minutes in a $40 \mathrm{mM}$ Trisacetate-EDTA buffer, pH 8.0 (TAE), the HP-CDs bands were visualized under a UV transilluminator at a wavelength of
$365 \mathrm{~nm}$ while DNA bands were visualized under the same condition after immersing in EB at about 10 minutes.

\subsection{Nucleic acid protective assay}

$5 \mu \mathrm{L}$ pre-diluted HP-CDs solution (2265 ng $\mu \mathrm{L}^{-1}$ ), $5 \mu \mathrm{L}$ RNA (3963 ng $\mu \mathrm{L}^{-1}$ ) and $5 \mu \mathrm{L}$ RNaseA $\left(10 \mathrm{mg} \mathrm{mL}^{-1}\right.$ ) were mixed (HPCDs-RNA-RNaseA) respectively as positive control for four groups, while $5 \mu \mathrm{L}$ dd $_{2} \mathrm{O}$ (double distilled water), $5 \mu \mathrm{L}$ RNA (3963 $\left.\mathrm{ng} \mu \mathrm{L}^{-1}\right)$ and $5 \mu \mathrm{L}$ RNaseA $\left(10 \mathrm{mg} \mathrm{mL}^{-1}\right)$ were complexed $\left(\mathrm{H}_{2} \mathrm{O}-\mathrm{RNA}-\mathrm{RNaseA}\right)$ as negative control as well as for four groups. Each group of HP-CDs-RNA-RnaseA and $\mathrm{H}_{2} \mathrm{O}-\mathrm{RNA}-$ RnaseA was incubated successively at $37^{\circ} \mathrm{C}$ in $60 \mathrm{~min}, 40 \mathrm{~min}$, $20 \mathrm{~min}, 0 \mathrm{~min}$. The trends were analyzed by electrophoresis for 20 minutes through a $2 \%$ agarose gel. The gel was run in a $40 \mathrm{mM}$ TAE and trends were stained using EB.

\subsection{Transfection experiment}

HEK-293T cells (human embryonic kidney 293T cells, ATCC number: CRL-11268) were used to identify transfection capability of HP-CDs. Plasmid PLV (red fluorescent protein) was chosen as reporter gene. HEK-293T cells were seeded at $1 \times 10^{5}$ per well in a 24-well plate which has already covered $14 \mathrm{~mm}$ diameter glass coverslips and incubated at $37{ }^{\circ} \mathrm{C}$ and $5 \% \mathrm{CO}_{2}$ overnight. $20 \mu \mathrm{L}$ pre-diluted HP-CDs $\left(100 \mu \mathrm{g} \mathrm{mL}{ }^{-1}\right)$ were mixed with $2000 \mathrm{ng}$ PLV and hold for $25 \mathrm{~min}$ at room temperature. After that, the complex was added in the hole blending with 2 $\mathrm{mL}$ culture medium. $24 \mathrm{~h}$ later, discarding the supernate and washing with PBS for 3 times. Then the cells were fixed with 1 $\mathrm{mL} 4 \%$ paraformaldehyde for 30 minutes at room temperature. After washing three times, Hoechst $33342\left(5 \mu \mathrm{g} \mathrm{mL}^{-1}\right)$ was used to stain nucleus for $30 \mathrm{~min}$. After washing with PBS, the coverslips was taken out and mounted by resin. Then confocal lasers scanning fluorescence microscopy was used to observe the transfection efficiency of HP-CDs.

\section{Results and discussion}

\subsection{The synthesis of HP-CDs}

The synthetic process of HP-CDs was given in Scheme 1. The mixture of HA and PEI experienced the process of dehydration, polymerization, aromatization and aromatization by hydrothermal process of $180^{\circ} \mathrm{C}$ for $4 \mathrm{~h}$. Finally, light yellow solution was dialyzed against distilled water to obtain highly fluorescent HP-CDs. In this experiment, a certain amount of PEI in the raw solution was necessary to enhance the HP-CDs formation which was critical for carbonization degree and carried positive charge combined with nucleic acid. HA endowed HP-CDs with targetspecific capability via interaction with CD44 molecules, which was the receptor of HA overexpressing in most tumour cells.

The formation process of carbon dots by carbonization between carboxyl and amino groups is extremely complicated, and a clear mechanism is still unknown. Based on previously reports $^{37,39}$ and our research, ${ }^{38}$ carbon dots may undergo dehydration, polymerization, aromatization and carbonization via hydrothermal reaction. These findings verified that the function of these molecules on the surface of resultant PEI-based carbon 


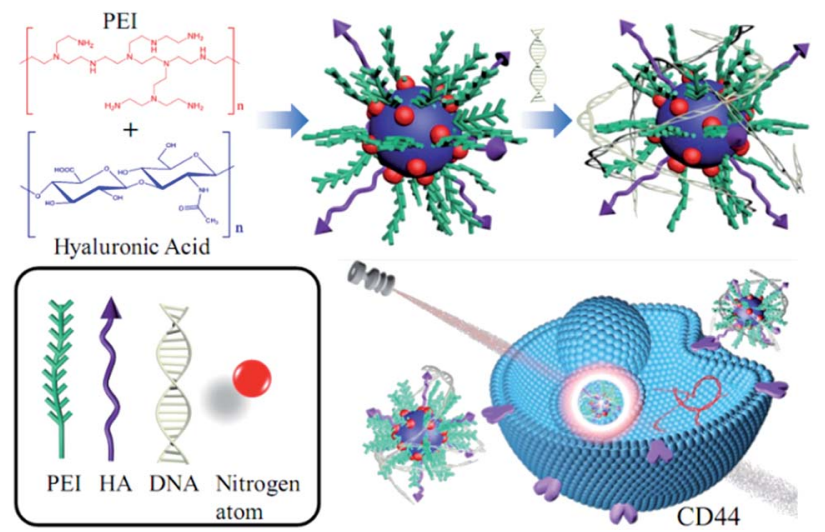

Scheme 1 Schematic synthesis of HP-CDs from hydrothermal carbonization method and following biomedical application.

dots was remained. In this study, dehydration and polymerization between amino groups of PEI and carboxyl groups of hyaluronic acid may form special construction structure similar to amphiphilic polymer structure, while the function of each other was not affected.

\subsection{The morphology and characterization of HP-CDs}

The morphology was identified by high-resolution transmission electron microscopy (HRTEM). As shown in Fig. 1A and B, HPCDs exhibited uniform dispersion and discrete quasispherical shape without apparent aggregation. HP-CDs have a well-defined structure of about $2.25 \mathrm{~nm}$ diameter, and such ultra-small size could be conducive to cross the physiological barrier and passive target to tumour tissue. The HRTEM (Fig. 1 inset) showed that HP-CDs were mainly composed of a carbon crystalline core with a lattice spacing of approximately $0.3 \mathrm{~nm}$, which reflected of the $\{002\}$ facet of graphite. In addition, a small amount of amorphous structure appeared at the particle edge locations. The results of TEM showed the HP-CDs possessed heterogeneous crystal phase structures.

The optical properties of HP-CDs were characterized by UV/ Vis spectrum (Fig. 1C) and photoluminescence (PL) spectrum (Fig. 1D). The HP-CDs aqueous solution exhibited a long-term homogeneous phase without any noticeable precipitation under ambient conditions at room temperature. The absorption spectrum (Fig. 1C) showed that just an absorption peak was observed at $352 \mathrm{~nm}$, which may give rise to a series of emission traps between $\mathrm{n}$ and $\pi^{*}$ states of the $\mathrm{C}=\mathrm{C}$. The HP-CDs aqueous solution was pale yellow and transparent in daylight but changed to bright blue fluorescence under UV excitation with quantum yield of $12.4 \%$, which could be easily observed with naked eyes (Fig. 1D, inset). As shown in Fig. 1D, the HP-CDs displayed broad range of emission wavelengths and the strongest emission peak shifts from $450 \mathrm{~nm}$ to $500 \mathrm{~nm}$ and the intensity decrease gradually as the excitation from $360 \mathrm{~nm}$ to $380 \mathrm{~nm}$. The strongest fluorescence emission was observed centered at approximately $470 \mathrm{~nm}$ under $350 \mathrm{~nm}$ excitation wavelength. This phenomenon has been widely observed in the luminescent carbon nanomaterials, which may be due to the
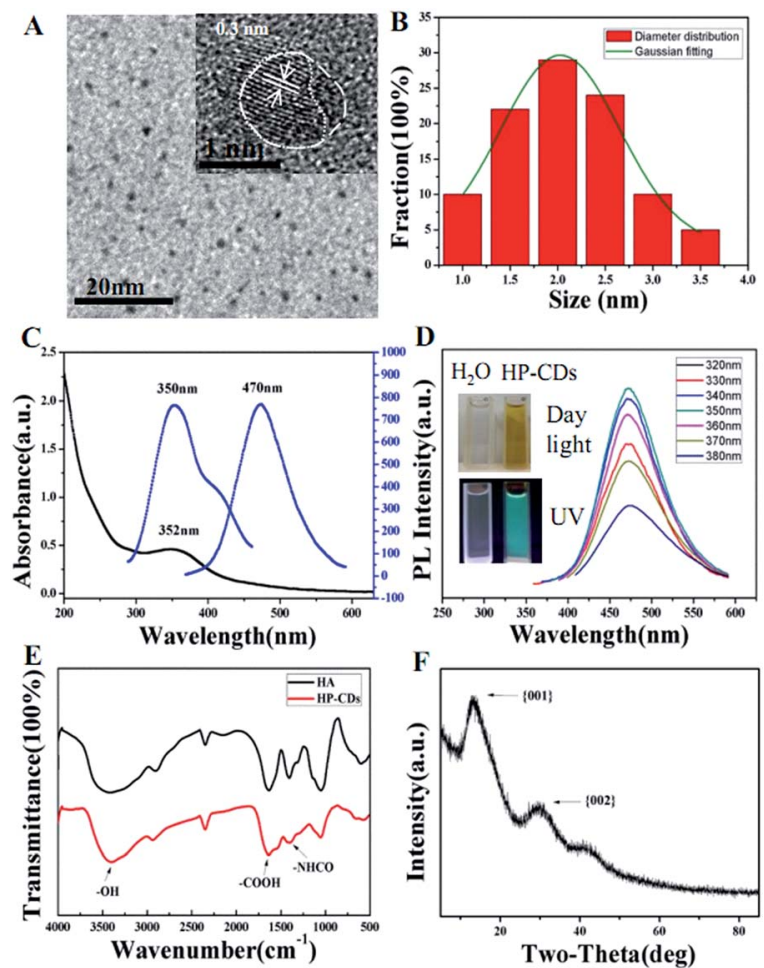

Fig. 1 Characterization of resultant HP-CDs. HR-TEM (A) and corresponding particle size distribution (B) of HP-CDs. UV-Vis absorbance (C) and photoluminescence emission spectra (D) of the HP-CDs with different excitation wavelength from $330 \mathrm{~nm}$ to $380 \mathrm{~nm}$ respectively. The inset (D) showed HP-CDs aqueous solution images under natural light and UV light. The FTIR spectrum (E) and XRD pattern (F) of the prepared HP-CDs.

optical selection of different surface defect states near the Fermi level of CDs. ${ }^{1}$ FT-IR spectra results indicated that there were a large number of the active groups on the surface of HP-CDs (Fig. 1E), such as the hydroxyl, carboxyl and acylamino groups, which endow HP-CDs with superior hydrophility and dispersibility in water. The crystal structure of HP-CDs was characterized by X-ray diffraction (XRD). As shown in Fig. 1F, the two broad main peaks centered at $X=13.42(d=0.74 \mathrm{~nm})$ and $X=29.45(d=0.3 \mathrm{~nm})$ indicated the amorphous nature of phase structure, which similar to the characteristic lattice spacing of graphene $\{002$ plane $\}$ and graphene oxide $\{001$ plane $\}$ respectively.

\subsection{The surface chemical structure of HP-CDs}

The surface chemical structure of the HP-CDs was characterized by X-ray photoelectron spectroscopy (XPS). As shown in Fig. 2A, there were three peaks separately at $285.0 \mathrm{eV}, 400.0 \mathrm{eV}$ and $530.0 \mathrm{eV}$, which illustrated that our as-prepared HP-CDs were truly composed of three elements including carbon, nitrogen and oxygen. In the high-resolution spectrum of $\mathrm{C}_{1 \mathrm{~s}}$ (Fig. 2B), the three main peak at 285.0 and $288.0 \mathrm{eV}$ represented $\mathrm{C}-\mathrm{C}$ and $\mathrm{C}=$ $\mathrm{N} / \mathrm{C}=\mathrm{O}$ respectively. The binding energy peak at $285.0 \mathrm{eV}$ demonstrated the HP-CDs had the structure of graphite-like, which was consistent with the results of XRD. As shown in 

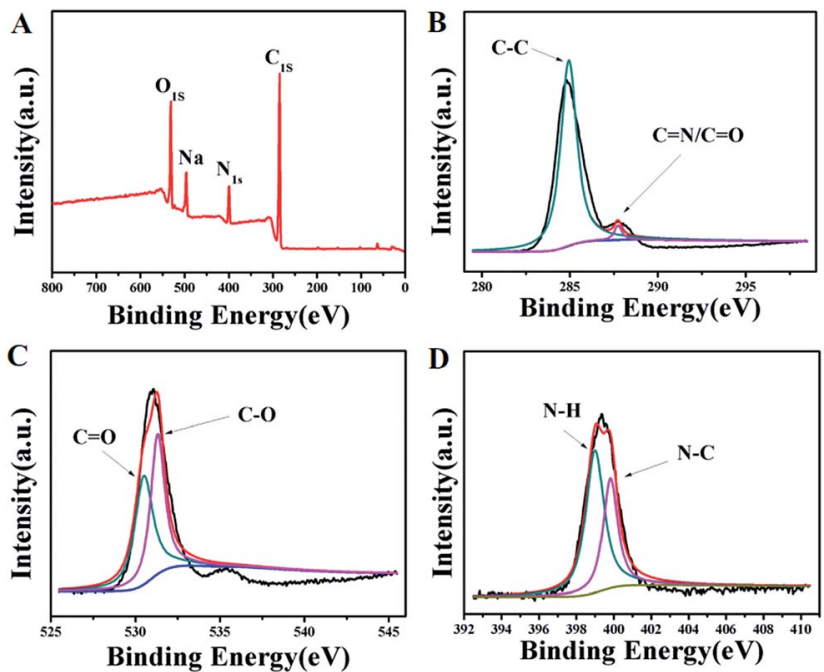

Fig. 2 XPS spectra of the HP-CDs. (A) Survey spectrum. (B) $C_{1 s}$ spectrum. (C) $\mathrm{O}_{1 \mathrm{~s}}$ spectrum. (D) $\mathrm{N}_{1 \mathrm{~s}}$ spectrum.

Fig. 2C, the spectra of $\mathrm{O}_{1 \mathrm{~s}}$ showed two conspicuous peak at $530.8 \mathrm{eV}(\mathrm{C}=\mathrm{O})$ and $532.2 \mathrm{eV}(\mathrm{C}-\mathrm{O})$, which was in agreement with the spectrum of $\mathrm{C}_{1 \mathrm{~s}}$. The remarkable $\mathrm{N}-\mathrm{H}$ peaks at $399.5 \mathrm{eV}$ and $\mathrm{N}-\mathrm{C}$ peak at $400.6 \mathrm{eV}$ of $\mathrm{N}_{1 \mathrm{~s}}$ (Fig. 2D) were corroborate the FTIR spectra of HP-CDs, which also confirmed the successful incorporation of $\mathrm{N}$ atoms into the HP-CDs by the hydrothermal treatment.

\subsection{Biomedical applications of HP-CDs}

The biocompatibility of HP-CDs, as potential biomedical agents, is critical for their biomedical application. The cytotoxicity of HP-CDs was investigated using CCK-8 in Hela cells. Compared with control group, no obvious toxicity was revealed with the increase of HP-CDs concentration from $50 \mu \mathrm{g} \mathrm{mL} \mathrm{m}^{-1}$ to $200 \mu \mathrm{g} \mathrm{mL}{ }^{-1}$ (Fig. 3A). Meanwhile, PBS treatment showed no influence on blood cells in Fig. 3B, but $\mathrm{dd}_{2} \mathrm{O}$ treatment gave rise to severe hemolysis phenomenon, which caused obvious increase of absorbance value at 541 and $575 \mathrm{~nm}$. On the contrary, each group absorbance of HP-CDs aqueous solution from different concentration with blood cells showed no obvious change by absorbance value compared with $\mathrm{dd}_{2} \mathrm{O}$ treatment group. The insert images in Fig. 3B showed that HPCDs resulted in no solution colour change caused by hemolysis after centrifugation. These results clearly suggested that the assynthesized HP-CDs had very low cytotoxicity and good hemocompatibility.

\subsection{The internalization and tumour cell imaging of HP-CDs}

The potential application of the as-prepared HP-CDs was evaluated by laser scanning confocal microscopy. After incubation with HP-CDs for $6 \mathrm{~h}$, the Hela cells were washed to remove extracellular HP-CDs and incubated with lysotracker for another $90 \mathrm{~min}$. It was found that the labelled cells were brightly illuminated due to strong fluorescence emitting from HP-CDs which distributed in cytosol (Fig. 3C). Consistent with optical
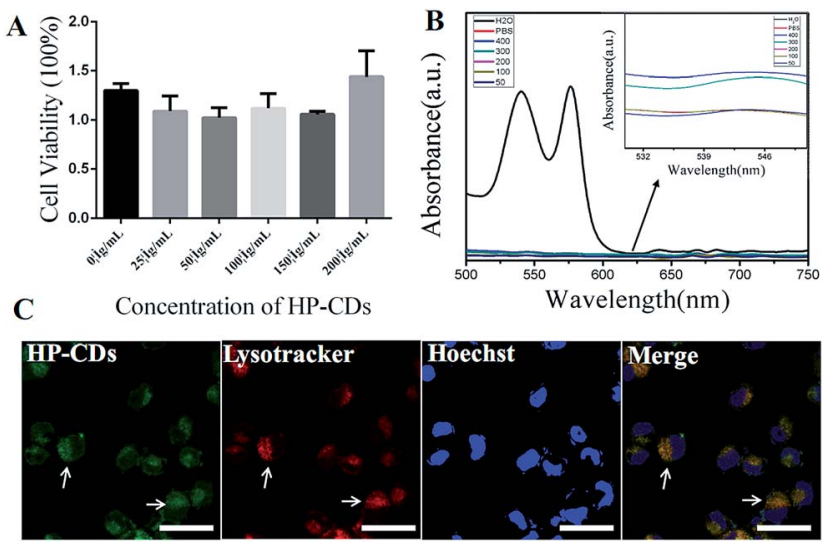

Fig. 3 (A) Cytotoxicity of the HP-CDs in Hela cells by CCK-8 assay. (B) Hemolytical activity of the HP-CDs at different concentration $(50,100$, 200,300 and $400 \mu \mathrm{g} \mathrm{mL}^{-1}$ ). PBS and water were used as negative and positive control, respectively. (C) Confocal microscopic images of Hela cells after incubation with HP-CDs. Blue represented nucleus; green represented HP-CDs; red represented lysotracker agent. The white bar represented $50 \mu \mathrm{m}$

results, the HP-CDs exhibited green fluorescence upon excitation $496 \mathrm{~nm}$. It was noted that the HP-CDs were clearly observed in cytoplasm regions, especially exhibited a co-location in the lysosomes with red fluorescence. In view of this result, we supposed that large amount of HP-CDs could be readily internalized into the cells across the cell membrane and further transferred to the lysosome. It might be explained by the fact that HP-CDs uptaken by cells could be internalized into the lysosomes via HA receptor-mediated endocytosis. These results gave us the conclusion that HP-CDs readily entered into the cytoplasm, which agreed well with the results of previous investigation on the interaction of living cells with other CDs. ${ }^{19,41,42}$ Thus, it can be seen that HP-CDs can be effectively applied in tumour cell imaging and biological labelling.

\subsection{The endocytosis of HP-CDs mediated by HA receptors}

In order to verify the HA receptor-mediated endocytosis, competitive inhibition test were employed via adding free HA molecules between HA-receptor high expression and low expression tumour cell lines. Natural HA macromolecule, a kind of main ingredient of extracellular matrix (ECM) and intercellular substance, could specific bind to CD44 which is a surface molecule over-expressed in cancer cells. Firstly, PCR assay was conducted to verify whether the HA functionalized HP-CDS could induce CD44 gene expression via interact with CD44 molecules. As shown in Fig. 4A, the increased CD44 signal intensity with the increased HP-CDs concentration demonstrated as-prepared HP-CDs could induce the gene expression of CD44 at RNA level.

Secondly, to prove the tumor-specific uptake behaviour of HPCDs by the HA receptor-mediated endocytosis, Hela cells with CD44-high as positive group expression and MCF-7 cells with CD44-low expression as negative group were chosen as the model cell lines. From flow cytometry analysis (Fig. 4B), it was found that Hela cells effectively took up a large number of HP-CDs, but the 

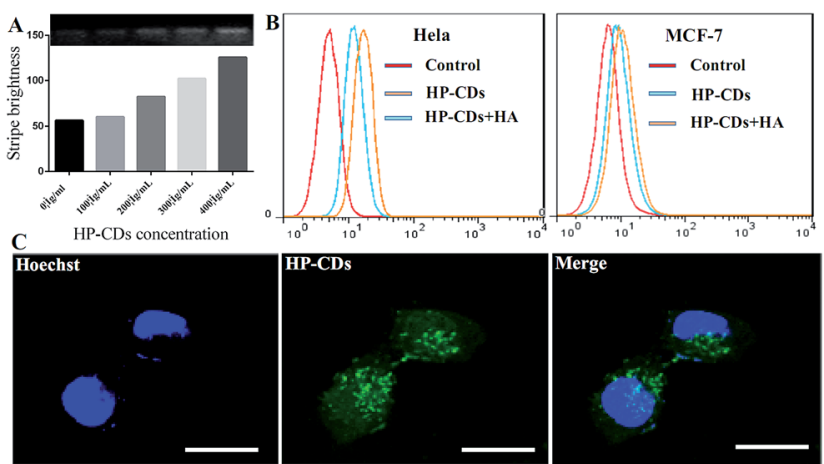

Fig. 4 Cellular uptaken of HP-CDs by HA receptor-mediated endocytosis. (A) CD44 gene expression by PCR after incubation with distinct concentration of $\operatorname{HP}$-CDs $\left(0,100,200,300\right.$ and $\left.400 \mu \mathrm{g} \mathrm{mL}^{-1}\right)$. (B) Fluorescence intensity of Hela cells was analyzed using FACS in different groups. (C) Confocal microscopy images of Hela cells after incubation with HP-CDs for $6 \mathrm{~h}$. The white bar represented $20 \mu \mathrm{m}$.

endocytosis behaviour was markedly inhibited after pre-treated free HA group. That may be because free HA molecules competitive bounded with CD44 and blocked the HP-CDs binding site, resulting in lower intake. However, the amount of HP-CDs by MCF-7 cells took up was lower and not significantly changed between free HA pre-treatment and not, which suggested that this competitive inhibition was disappeared. According to the confocal microscopy images (Fig. 4C), it was further confirmed that HP-CDs could really distribute in cytosols of Hela cells. All mentioned-above suggested that HP-CDs could be effectively taken up by the HA receptor-mediated endocytosis and serve as cell-specific targeting probe for imaging and labeling of CD44high expression tumor cells.

\subsection{Nucleic acid condensation and transfections of HP-CDs}

As depicted in Scheme 1, we speculated that the PEI functionalized HP-CDs may be capable of condensing nucleic acid molecules by electrostatic interactions. Thus, the surface charge of HP-CDs/pDNA complexes was measured to determine the ability of cationic vectors to condense DNA. The zeta potential data revealed (in Fig. 5A) that of HP-CDs displayed highest potential, free DNA showed lowest potential. However, the potential was obviously neutralized but still a positive charge, when HP-CDs bounded with pDNA complexes. Next, gel retardation assay was further used to illustrate whether HP-CDs possessed the capacity of condensing DNA (Fig. 5B). The HPCDs were mixed with DNA at different weight ratios (DNA/HPCDs) to form DNA/HP-CDs complexes. DNA with the negative charge run toward positive pole but HP-CDs with positive charge run toward negative pole in the electrophoresis process. As can be seen from Fig. 5B, with the increasing weight of HPCDs, they showed increased fluorescence while the intensity of DNA migration band decreased significantly and finally disappeared at the DNA/HP-CDs weight ratio of $1: 3$. This result confirmed that HP-CDs indeed have the capability of condensing and loading nucleic acid substances.

We further investigated whether HP-CDs could prevent nucleic acid from the RnaseA degradation. $5 \mu \mathrm{L}$ pre-diluted HP-
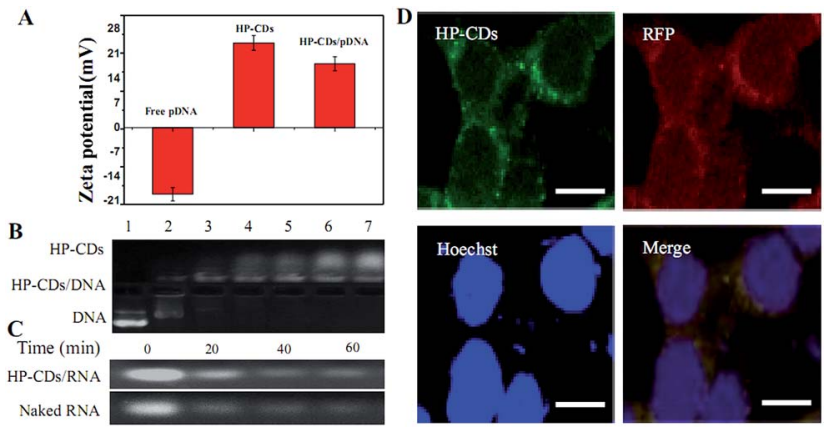

Fig. 5 Nucleic acid condensation, protection and transfection of HPCDs. (A) The zeta potential of free DNA, HP-CDs and HP-CDs/DNA complex. (B) Gel retardation assay of the HP-CDs/plasmid complexes with various ratios ranging from $1: 0$ to $1: 6$. (C) Agarose gel electrophoresis of RNA protected by HP-CDs under RnaseA degradation at different time from 0 to $60 \mathrm{~min}$. (D) Identification of transfection efficiency of HP-CDs. Fluorescent images of PLV expression obtained by a confocal laser scanning microscope in HEK-293T cells transfected with DNA/HP-CDs complexes. Incubation time: 24 h; blue represented nucleus; green represented HP-CDs; red represented red fluorescent protein. The white bar represented $10 \mu \mathrm{m}$.

CDs solution (2265 ng $\mu \mathrm{L}^{-1}$ ) mixed with $5 \mu \mathrm{L}$ RNA (3963 ng $\left.\mu \mathrm{L}^{-1}\right)$ and $5 \mu \mathrm{L}$ RnaseA $\left(10 \mu \mathrm{g} \mathrm{mL}^{-1}\right)$ were prepared as the experimental group, while $5 \mathrm{~mL} \mathrm{dd}_{2} \mathrm{O}$ mixed with abovementioned $5 \mu \mathrm{L}$ RNA (3963 ng $\left.\mu \mathrm{L}^{-1}\right)$ and $5 \mu \mathrm{L}$ RnaseA $(10 \mu \mathrm{g}$ $\mathrm{mL}^{-1}$ ) were prepared as control group. The four samples of each group were respectively incubated in $37^{\circ} \mathrm{C}$ from 0 to $60 \mathrm{~min}$. As shown in Fig. 5C, with the incubation time prolonging, the degradation of RNA were relieved by the protection of HP-CDs compared with the control group especially until $60 \mathrm{~min}$. These data demonstrated that HP-CDs showed favourable nucleic acid protective function.

To illustrate the transfection efficiency of HP-CDs, gene transfection experiment in HEK-293T cells were performed by using PLV which enhancing red fluorescence as the reporter gene in order to differentiate with green fluorescence of HP-CDs. As can be seen from Fig. 5D, the nucleus was dyed blue with Hoechst 33342. Intrinsic green fluorescence endowed HP-CDs with advantageous real-time tracking as living cells probe. The present of green fluorescence showed the HP-CDs have been readily internalized into cytoplasm, which may be regulated by HA receptor-mediated endocytosis. Bright red fluorescence of PLV could be observed from the cytoplasm, which indicated the successful delivery and expression of PLV. These images indicated that the HP-CDs not only served as fluorescence probe could real-time monitor the internalization by receptor-mediated endocytosis, but also as efficient gene vector could carry exogenous gene into the cell. More importantly, these transfected genes could escape from lysosome and effectively express to produce gene product, which may be caused by the protonation of polycation on the surface of HP-CDs.

\section{Conclusions}

In summary, we synthesized a kind of novel multifunctional HP-CDs through a facile and simple bottom-up route. The asprepared HP-CDs possessed stable photoluminescence, 
superior disperbility in water and surface biocompatibility. The application of HA modification in HP-CDs interacting with CD44 was applied to targeting to tumour cells. Furthermore, in this efficient nano-carrier system, PEI played two crucial roles: endow the HP-CDs with intense photoluminescence by surface passivation and DNA condensation for gene transfection. Furthermore, we further demonstrated that HP-CDs with good biocompatibility were easily and fast internalized by cancer cells and particularly suitable for real-time cellular imaging and labelling.

\section{Acknowledgements}

The research was supported by the National Natural Science Foundation of China (No. 81301316, 31200676), China Postdoctoral Science Foundation (2013M540425, 2014T70487, 2015M571705), Health and family planning commission of Jiangsu province scientific research subject (H201557), Natural Science Foundation of Jiangsu Province (BK20161317), Senior Talents Scientific Research Foundation of Jiangsu University (No. 13JDG022, 11JDG113).

\section{Notes and references}

1 S. N. Baker and G. A. Baker, Angew. Chem., Int. Ed. Engl., 2010, 49, 6726-6744.

2 A. L. Himaja, P. S. Karthik and S. P. Sigh, Chem. Rec., 2015, 15, 595-615.

3 Y. P. Sun, B. Zhou, W. Wang, K. A. Shiral Fenando, P. Pathak and M. J. Meziani, J. Am. Chem. Soc., 2006, 128, 7756-7757.

4 D. Chen, N. A. Monteiro-Riviere and L. W. Zhang, Wiley Interdiscip. Rev.: Nanomed. Nanobiotechnol., 2016, DOI: 10.1002/wnan.1419.

5 F. Zhang, X. Feng, Y. Zhang, L. Yan, Y. Yang and X. Liu, Nanoscale, 2016, 8, 8618-8632.

6 Q. L. Wang, X. X. Huang, Y. J. Long, X. L. Wang, H. J. Zhang and R. Zhou, Carbon, 2013, 59, 192-199.

7 E. Keles, Y. Song, D. Du, W. J. Dong and Y. H. Lin, Biomater. Sci., 2016, 4, 1291-1309.

8 A. W. Zhu, Q. Qu, X. L. Shao, B. Kong and Y. Tian, Angew. Chem., Int. Ed. Engl., 2012, 51, 7185-7189.

9 H. T. Li, X. D. He, Z. H. Kang, H. Huang, Y. Lin and J. L. Liu, Angew. Chem., Int. Ed. Engl., 2010, 49, 4430-4434.

10 M. Long, A. N. Hoang, J. Chung, N. Gural, C. B. Ford and C. Min, Nat. Commun., 2013, 4, 216-219.

11 D. Wu, Y. Jiang, S. Y. Li, F. Z. Li, J. W. Li and X. Z. Lan, Nanotechnology, 2011, 22, 3785-3793.

12 J. J. Huang, Z. F. Zhong, M. Z. Rong, X. Zhou, X. D. Chen and M. Q. Zhang, Carbon, 2014, 70, 190-198.

13 S. Patra, E. Roy, R. Madhuri and P. K. Sharma, Biomater. Sci., 2016, 4, 418-429.

14 Y. Yang, J. C. Zhang, J. Zhuang and X. Wang, Nanoscale, 2015, 7, 12284-12290.

15 Q. H. Liang, W. J. Ma, Y. Shi, Z. Li and X. M. Yang, Carbon, 2013, 60, 421-428.
16 C. Z. Zhu, J. F. Zhai and S. J. Dong, Chem. Commun., 2012, 48, 9367-9369.

17 S. N. Qu, X. Y. Wang, Q. P. Lu, X. Y. Liu and L. Y. Wang, Angew. Chem., Int. Ed. Engl., 2012, 51, 12215-12218.

18 R. Zhang, Y. B. Liu, L. B. Yu, Z. Li and S. Q. Sun, Nanotechnology, 2013, 24, 225601.

19 F. Y. Du, J. Yuan, M. M. Zhang, J. N. Li, Z. Zhou and Z. Li, RSC Adv., 2014, 4, 37536-37541.

20 W. C. Yen and W. W. Lamph, Prostate, 2006, 66, 305-316.

21 A. K. Yadav, P. Mishra, S. Jain, P. Mishra, A. K. Mishra and G. P. Agrawal, J. Drug Targeting, 2008, 16, 464-478.

22 S. Ganesh, A. K. lyer, F. Gattacceca, D. V. Morrissey and M. M. Amiji, J. Controlled Release, 2013, 172, 699-706.

23 K. K. Vangara, J. L. Liu and S. Palakurthi, Anticancer Res., 2013, 33, 2425-2434.

24 K. Cohen, R. Emmanuel, E. Kisinfinfer, D. Shabat and D. Peer, ACS Nano, 2014, 8, 2183-2195.

25 S. C. Ghosh, A. S. Nesihan and J. Klostergaard, Expert Opin. Ther. Targets, 2012, 16, 635-650.

26 C. E. Galer, D. Sano, S. C. Ghosh, J. H. Hah, E. Auzenne and A. N. Hamir, Oral Oncol., 2011, 47, 1039-1047.

27 H. J. Cho, H. Y. Yoon, H. Koo, S. H. Ko, J. S. Shim and J. H. Lee, Biomaterials, 2011, 32, 7187-7190.

28 R. E. Eliaz and F. C. Szoka Jr, Cancer Res., 2001, 61, 25922601.

29 W. Hyung, H. Ko, J. Park, E. Lim, S. B. Park and Y. J. Park, Biotechnol. Bioeng., 2008, 99, 442-454.

30 J. Yao, Y. Fan, R. H. Du, J. P. Zhou, Y. Lu and W. Wang, Biomaterials, 2010, 31, 9357-9365.

31 B. O. Boussif, F. Lezoualc'H and M. A. Zanta, Proc. Natl. Acad. Sci. U. S. A., 1995, 92, 7297-7301.

32 A. E. Nel, L. Madler, D. Velegol, X. Tian, E. M. V. Hoek and P. Somasundaran, Nat. Mater., 2009, 8, 543-557.

33 R. Z. Ur, D. Hoekstra and I. S. Zuhorn, ACS Nano, 2013, 7, 3767-3777.

34 M. Breunig, C. Hozsa, U. Lungwitz, K. Watanabe, I. Umeda and H. Kato, J. Controlled Release, 2008, 130, 57-63.

35 L. Hu, Y. Sun, S. Li, X. Wang, K. Hu, L. Wang, X. Liang and Y. Wu, Carbon, 2014, 67, 508-513.

36 Q. Wang, C. Zhang, G. Shen, H. Liu, H. Fu and D. Cui, J. Nanobiotechnol., 2014, 12, 58.

37 C. Liu, P. Zhang, X. Zhai, F. Tian, W. Li, J. Yang, Y. Liu, H. Wang, W. Wang and W. Liu, Biomaterials, 2012, 33, 3604-3613.

38 S. K. Bhunia, A. Saha, A. R. Maity, S. C. Ray and N. R. Jana, Sci. Rep., 2013, 3, 1473.

39 L. Hu, Y. Sun, S. Li, X. Wang, K. Hu, L. Wang, X. Liang and Y. Wu, Carbon, 2014, 67, 508-513.

40 F. Du, J. Yuan, M. Zhang, J. Li, Z. Zhou and Z. Li, RSC Adv, 2014, 4, 37536-37541.

41 F. Du, X. Jin, J. Chen, Y. Hua, M. L. Gao and L. Zhang, J. Nano Res., 2014, 16, 1-10.

42 F. Du, J. Li, Y. Hua, M. Zhang, Z. Zhou and Y. Jing, J. Biomed. Nanotechnol., 2015, 11, 780-789. 